\title{
Not Known if BRAF Rearrangement Analysis Was Performed
}

National Cancer Institute

\section{Source}

National Cancer Institute. Not Known if BRAF Rearrangement Analysis Was Performed. NCI Thesaurus. Code C160434.

An indication that it is not known whether BRAF rearrangement analysis was performed during the study. 